${ }^{I}$ Universidade Federal do Rio de Janeiro (UFRJ), Brasil

lucascarvalho@globo.com

Lucas Correia Carvalho'

\title{
SOBRE IDENTIDADES INTELECTUAIS E PRÁTICAS SOCIAIS
}

Sociologia no espelho. Ensaístas, cientistas sociais e críticos literários no Brasil e na Argentina (1930-1970). (2014). Jackson, Luiz Carlos \& Blanco, Alejandro. São

Paulo: Ed. 34, 264 p.

O livro Sociologia no espelho. Ensaístas, cientistas sociais e críticos literários no Brasil e na Argentina (I930-I970) de Luiz Carlos Jackson e Alejandro Blanco é um dos mais novos resultados de um empreendimento coletivo que propõe a comparação de sistemas intelectuais nos dois países e vem proporcionando o fluxo de pesquisadores e o fortalecimento de vínculos entre instituições acadêmicas brasileiras e argentinas. No Brasil, a coordenação cabe a Sergio Miceli, na Argentina, a Carlos Altamirano com o grupo da revista Prismas, no Centro de História Intelectual da Universidade Nacional de Quilmes. Este intercâmbio, como registra a seção "Agradecimentos", já rendeu importantes publicações, como os dois volumes de Historia de los intelectuales en América Latina, coordenados por Carlos Altamirano, e Vanguardas em retrocesso, de autoria de Sergio Miceli (resenhada nesta revista no volume 3, número 6, 2013). Está prevista, ainda, a publicação da coletânea de Retratos latino-americanos, organizada por Jorge Myers e Sergio Miceli, sobre a memorialística nos dois países.

Sociologia no espelho toma como marco comparativo os momentos iniciais do longo processo de institucionalização da sociologia nos dois contextos nacionais, circunscritos entre as décadas de i930 e I970. A escolha da Argentina e do Brasil é justificada com base no avançado grau de institucionalização atingido pela disciplina nesses países graças a 
iniciativas nacionais. Esse aspecto se destaca quando se comparam outras experiências latino-americanas, como a do Chile, onde empreendimentos internacionais, como a Faculdade Latino-Americana de Ciências Sociais (FLACSO), tiveram papel proeminente. No caso do Brasil, são adotados no livro como momentos representativos a fundação da Escola Livre de Sociologia e Política (ELSP), em I933, e da Faculdade de Filosofia, Ciências e Letras da Universidade de São Paulo (FFCL/ USP), em I934. Na Argentina, havia, desde I898, o Instituto de Sociologia da Faculdade de Filosofia e Letras da Universidade de Buenos Aires (FFyL/ UBA), vinculado a cursos de direito e filosofia, embora a disciplina tenha se tornado autônoma somente em I958, na mesma universidade. Em ambos os países, justificam os autores, seria possível identificar uma cultura intelectual afinada com certos padrões científicos (trabalho em equipe, utilização de uma linguagem científica, esforço em aliar rigor teórico e fundamentação empírica) que foram, aos poucos, eleitos como critérios de desempenho profissional na área. Considerando seus contextos locais específicos, os autores demonstram nessa reconstituição de que maneira diversos "gêneros" - ensaio, sociologia científica e crítica literária -, em suas relações recíprocas, contribuíram para o aprofundamento dos respectivos processos de institucionalização. Para tanto, a principal via analítica percorrida foi classificar as diferentes identidades intelectuais - aqueles que se definem e são definidos como "ensaístas", "sociólogos profissionais" e "críticos literários" - e as práticas sociais que as alicerçam - trajetória familiar, relações profissionais, posições e oposições acadêmicas.

O leitor é advertido que o trabalho de comparação apresentado se circunscreveria inicialmente às figuras que melhor teriam assumido o feitio da moderna sociologia latino-americana: o ítalo-argentino Gino Germani e o brasileiro Florestan Fernandes. Contudo, a pesquisa se ampliou, de modo a abarcar tanto as tradições intelectuais pretéritas que se imiscuíram nesse processo de institucionalização, quanto as repercussões ou vínculos da sociologia com outras áreas, especificamente a crítica literária. A relação entre identidades intelectuais e práticas sociais que embasa a comparação é profícua para o entendimento desse processo. Porém, a análise levada a cabo pelo livro sobre a diferenciação das áreas de conhecimento e dos gêneros citados, no momento mesmo em que eram postos em tensão por seus praticantes, não inclui de modo mais sistemático a produção textual como dimensão fundamental das práticas intelectuais. Isso permitiria nuançar a relação entre os gêneros destacados e seus contextos locais, além da comparação propriamente dita.

O primeiro capítulo, intitulado "A batalha dos gêneros", apoia-se na constatação de que, diferente do que ocorrera na Argentina, no Brasil certo conjunto de temas e formula- 
ções de pesquisa foram legados pelo ensaísmo à sociologia acadêmica. $\mathrm{Na}$ Argentina, o ensaísmo de feição política precedeu a formação de um campo literário, processo que acompanhou intimamente sua conturbada história, que desde a Independência, em I8Io, ficou marcada pelo enlace decisivo entre os intelectuais e a política. Processo inverso se realizou no Brasil. Aqui, desde a Independência, proclamada pacificamente em I822 e marcada pela continuidade do regime imperial -, a literatura, sobretudo a poesia e o romance, antecedeu o ensaísmo político. Estas características peculiares a cada sistema intelectual - embora já apresentassem influxos importantes - teriam seus sentidos invertidos com o ensaísmo dos anos I930, momento em que mudanças políticas de monta, como a reação à política oligárquica no Brasil e a interrupção da experiência de democratização dos governos radicais na Argentina, desencadearam atitudes distintas entre os intelectuais, com tom otimista, no primeiro caso, e pessimista, no segundo. Tudo isto teria repercussão direta na forma preponderante assumida pelo ensaísmo em cada sistema intelectual: no caso argentino, este tendeu cada vez mais à literatura, enquanto no país vizinho, dado "um certo grau de abertura política” (p. 40), ressaltou-se seu caráter sociológico. Postos lado a lado, os processos de formação do sistema intelectual em cada país explicariam aquela constatação inicial, evidenciando ainda como o perfil do ensaís- mo brasileiro da década de I930, momento em que a sociologia começava a se definir como disciplina acadêmica, teve como correlato a forte reação dos sociólogos àquele gênero.

Gino Germani e Florestan Fernandes, próceres da sociologia em seus moldes modernos, teriam forjado suas identidades intelectuais justamente em contraposição ao ensaísmo, ao impulsionarem a pesquisa empírica e monográfica. Tal reação, segundo Jackson e Blanco, seria ainda mais marcada pelas experiências sociais ensejadas pelas duas metrópoles, São Paulo e Buenos Aires. Neste particular, os autores retomam alguns dos marcos comparativos já explorados em trabalhos reunidos em História das ciências sociais no Brasil (Sumaré/Anpocs, 200I), ao chamarem a atenção para a particularidade da institucionalização da sociologia em São Paulo - configurada por experiências acadêmicas com alta adesão aos padrões científicos -, em relação à do Rio de Janeiro - onde os constrangimentos políticos teriam limitado uma situação análoga. Buenos Aires condensaria, todavia, estas duas experiências, a paulista e a carioca: desfrutava de um sistema universitário há muito estabelecido, ao mesmo tempo que as constantes intervenções políticas nas universidades não impediram a proeminência de Gino Germani nem arrefeceram o ímpeto que ele representava em relação às pesquisas empírica e teórica. Interessante notar, contudo, que o lugar ocupado por Buenos Aires na comparação efetu- 
ada pelos autores permite repor em outros termos a relação entre ciência e política, sem que a força de uma implique a fraqueza da outra. Isto poderia ser demonstrado, por um lado, nos casos tidos como adversos aos modernos padrões cognitivos das ciências sociais, como o Rio de Janeiro, onde, não obstante, emergiu uma figura com extremo rigor acadêmico como Luiz Costa Pinto; e, por outro lado, em relação a São Paulo, onde a relativa fraqueza da pressão política sobre o sistema educacional não impediu que os sociólogos inscrevessem na vida pública seus temas e debates.

No terceiro e último capítulo, intitulado "Terrenos da crítica", Jackson e Blanco demonstram como a crítica literária, a partir da década de I950, utilizou-se dos instrumentos sociológicos para se legitimar como disciplina científica. Na Argentina, as mudanças no mercado cultural, sobretudo com a criação de revistas literárias, acirraram as disputas entre, de um lado, os críticos literários, em sua maioria descendentes de imigrantes, e, de outro lado, os escritores de extração social criolla, cujo maior expoente era Jorge Luis Borges. Esta polarização teria efeitos diretos nos debates intelectuais, já que os críticos literários profissionais passaram a questionar o monopólio da exegese de textos reivindicado pelos escritores. Os embates daí decorrentes se deixariam ver na trajetória do crítico argentino Adolfo Prieto, descendente de imigrantes espanhóis e com formação acadêmica em letras, que incorporou a sociologia como modo de interpretação externa aos textos. No Brasil, a crítica literária entraria na universidade tardiamente em comparação ao caso argentino, e teria na figura de Antonio Candido o principal articulador dessas áreas disciplinares em São Paulo. Diferente de Pietro, Candido, que era descendente de uma família tradicional e graduado em ciências sociais pela USP, migrando posteriormente para o curso de letras, reivindicava a autonomia relativa do texto, meio pelo qual construiria sua identidade intelectual como crítico literário e se afastaria da sociologia. A diferença dos estilos de crítica entre Pietro e Candido se explicaria também pelo fato de este último não ter lidado com disputas análogas àquelas travadas no campo intelectual argentino.

Embora esta seja uma questão da própria matéria que cabe aos autores analisar, isto é, que se inscreve no universo dos objetos, pode-se perguntar se a perspectiva institucionalista adotada na análise das identidades intelectuais não tende a minimizar as tensões entre texto e contexto e as ambiguidades das relações da sociologia acadêmica com as tradições ensaísticas. Se os autores alertam para a continuidade de temas e proposições do ensaísmo na sociologia institucionalizada - em menor medida no caso argentino -, deixam, entretanto, de notar aspectos da crítica dos sociólogos que não se referiam somente ao caráter pré-científico daquele gênero, a exemplo do embate entre Florestan Fernandes e Gilberto Freyre. Isto porque, para além do diletantismo inte- 
lectual de que Freyre era acusado, as ideias se constituem em forças sociais que informam e são informadas por diversos agentes, e revelam dinâmicas reais da sociedade, como, ademais, apontava Fernandes em pesquisas sobre a integração social do negro e o papel deletério desempenhado pela ideologia da democracia racial. Do mesmo modo, os próprios autores fornecem elementos importantes para se pensar como dois dos principais livros de Antonio Candido, Os parceiros do Rio Bonito (I954), tese de doutoramento cujo intento era analisar a relação entre literatura e sociedade, e Formação da literatura brasileira (I959), jogam luz um no outro pelo modo como apresentam uma interpretação da formação da sociedade brasileira (p. 2I3-2I5). Por sinal, como o próprio Jackson já o fizera em seu livro
A tradição esquecida (2002). Contudo, os autores não tratam os livros de Candido como uma variável forte, ao lado da trajetória acadêmica, capazes de explicar o perfil de crítica literária praticada pelo autor.

Importante dizer que foi justamente Antonio Candido, no clássico "A sociologia no Brasil", quem viu no "sincretismo" uma das principais características de nossa sociologia, fruto de uma tenaz resistência dos nós que amarram aqueles diferentes gêneros indicados no livro. Esta característica, quando posta lado a lado com aquela de outros sistemas intelectuais, como o fazem Jackson e Blanco, perde seu traço de obviedade e pode surpreender pelas questões que a envolvem e que nos dizem respeito ainda hoje.

Recebida em 24/04/20I5 | Aprovada em 27/05/2015

Lucas Correia Carvalho é doutor em Sociologia pelo Programa de PósGraduação em Sociologia e Antropologia (PPGSA) da Universidade Federal do Rio de Janeiro (UFRJ), com período sanduíche na École des Hautes Études em Sciences Sociales (EHESS). Atualmente é professor substituto no Departamento de Sociologia da UFRJ. Suas pesquisas situam-se na área do pensamento social brasileiro e da história das ciências sociais e seus projetos de pesquisa. 